\title{
An Assessment Of Instructional Module In Basic And Higher Educational Institutions In Zambales: Plagiarism Issues
}

\author{
Froilan D. Mobo \\ Assistant Director, Department of Research and Development \\ Philippine Merchant Marine Academy \\ Philippines \\ froilanmobo@gmail.com \\ Abdul Rahmat \\ Gorontalo State University, Indonesia \\ abdulrahmat@ung.ac.id
}

Received: 12 Januari 2021; Revised: 26 Februari 2021; Accepted: 28 April 2021 DOI: http://dx.doi.org/10.37905/aksara.7.2.367-370.2021

\begin{abstract}
During the full Implementation of flexible learning in both basic and higher education, the majority of the schools opted to choose to use a modular approach rather than online learning. There are a lot of struggles encountered by both teachers and students. Part of the Struggle is the development of modular instructional materials. There are teachers that accidentally didn't cite credible sources which reflected in their modules. Book Authors also suffered from copywriting and plagiarism issues because there are teachers that don't know how to cite or give credit to the authors of the book or in some published research. This study will help both teachers and administrators of both basic and higher education on how to formalize a standard method on how to cite credible sources just like in a refereed research journal.
\end{abstract}

Keywords: Plagiarism, Copy writing, module

\section{INTRODUCTION}

The Educational Sector had shifted into a new normal approach and there are a lot of challenges being encountered and part of those challenges during the full Implementation of flexible learning in both basic and higher education, the majority of the schools opted to choose to use a modular approach rather than online learning. Even the website depedcommunity.com are allegedly replicating the articles of TeacherPH, appealing them as their reports, is owned by DepEd teachers, (Llego, 2020) There are a lot of struggles encountered by both teachers and students. Part of the Struggle is the development of modular instructional materials. Some teachers accidentally didn't cite credible sources that reflected in their modules in most Higher Education and Department of Education in Zambales. With the number of modules to prepare, the teachers have to remedy to the easiest and the fastest way of finishing their tasks is to copy paste from already existing materials, either from the internet, and/or from books which most of our member 
authors have conscientiously written and published, (Mutya, 2020). Book Authors also suffered from copywriting and plagiarism issues because there are teachers that don't know how to cite or give credit to the authors of the book or in some published research. Plagiarism directed academic misconduct by students and by the academician. The reaction by the experts tends to be one of the most discipline and punishment, at all times, (Hannabuss, 2001). Plagiarism is the most common problem today in the academic community because it measures the integrity of an author how whether she or he had cited the author properly. Book and Journal Publications only allows 30\% similarity indexes before they will accept the manuscript for publication. Even ESL teachers may have difficulties in dealing with plagiarism because they are cognizant that it is a thought which is already practiced in western cultures, (Hyland, 2001). This study will help both teachers and administrators of both basic and higher education on how to formalize a standard method on how to cite credible sources just like in a refereed research journal and book publication.

\section{OBJECTIVES}

The main objective of the study is the Assessment of Instructional Module in both Higher Education and Basic Education in terms of Plagiarism issues. Specifically, the study seeks to find answers to the following questions:

1. To examine the level of awareness of the students and teachers about plagiarism issues;

2. To recommend steps in avoiding plagiarism

\section{METHODOLOGY}

A well structured questionnaire was developed using Google form to collect data from the respondents. A total of 100 questionnaires were randomly distributed among the Higher and Basic Education in Zambales. A five point likert scale from 1 to 5 towards the assessment of modules in higher and basic education in terms of plagiarism. After careful collating all the data from the database of Google form it will be analyse and interpreted according to the given results. The data will be presented in graphical chart.

\section{RESULTS} form.

A total of 100 respondents answered my survey questionnaire using google
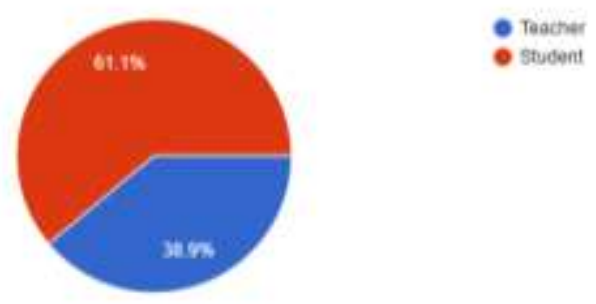

Figure 1 . There are $61.1 \%$ Students who had answered the survey questionnaire using Google Form coming form different both public and private Basic Education 
and Higher Education and there are also $38.9 \%$ Teachers who have answered the survey questionnaire using Google Form representing all educational institutions from the Province of Zambales.

Level of awareness of the students and teachers about plagiarism issues:
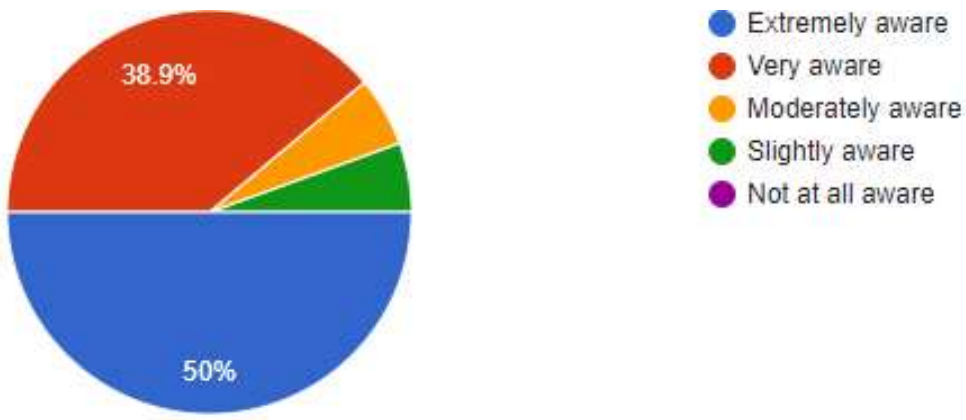

Not at all aware

Figure 2: Shows that there are 50\% who are extremely aware about the plagiarism issues and $38.9 \%$ who are very aware about the plagiarism issues by both teachers and students in higher educational institutions and basic educational institutions, the rest they are moderately aware, slightly award and not at all are aware. With the figure 2 there is a need to adapt a method to avoid plagiarism issues.

Steps in avoiding plagiarism

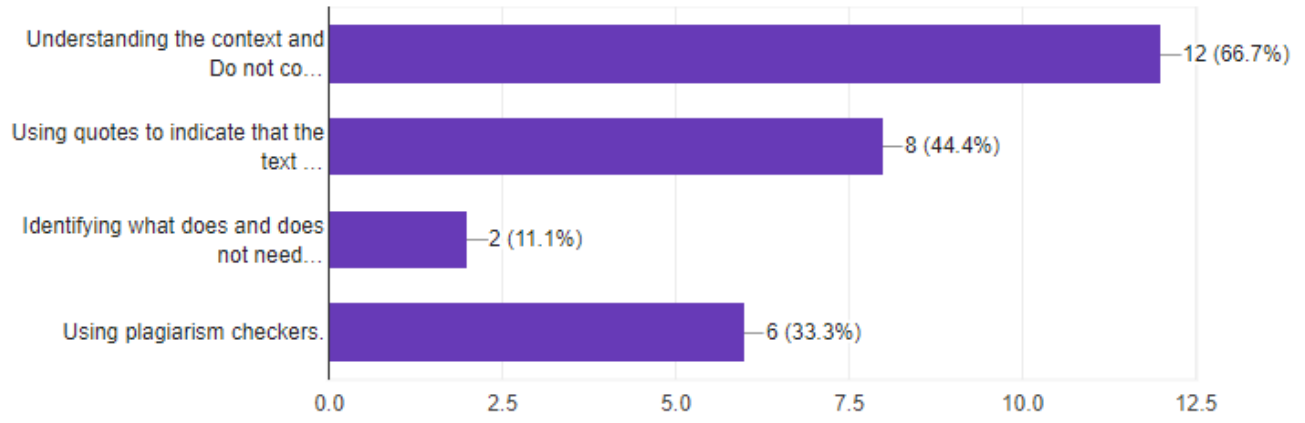

Figure 3. Shows that the following steps should be done cohesively because $66.7 \%$ mentioned that there is a need to understand the context and do not copy and paste, $44.4 \%$ mentioned and there is a need to use quotations every time we cite papers. $11.1 \%$ is to identify what does and does need to cite. $33 \%$ agreed to use plagiarism checker online. 


\section{DISCUSSIONS}

The analysis reveals that $50 \%$ of the students are extremely aware and $38.9 \%$ of the teachers are very aware of the plagiarism issues on assessment of instructional module. Also both teachers and students are recommending certain steps to avoid plagiarism issues.

\section{CONCLUSIONS}

The study shows that teachers and students are extremely and very aware of the plagiarism issues on the assessment of the instructional module, and it is important to follow certain steps to avoid plagiarism such as (1) understand the context and do not copy and paste; (2) there is a need to use quotations every time we cite papers; (3) to identify what does and does need to cite; and (4) use plagiarism software. The Similarity index acceptance from both local and international book and journal publications are between $20 \%$ to $30 \%$ similarity index. It also showed a significant decrease in the similarity index of the submitted manuscripts of the teacher education students before and after the manuscript was scanned and filtered using plagiarism software., (Roman, 2018)

\section{Recommendations}

It is highly recommended that all educational institutions must purchase and use an online plagiarism checker to avoid a similarity index and this is to produce quality papers for possible international presentations and publications in book and journal publishing.

\section{References}

Hannabuss, S. (2001). Contested texts: Issues of plagiarism. Retrieved From https://www.emerald.com/insight/content/doi/10.1108 /EUM0000000005595/full/html

Hyland, F. (2001). Dealing with plagiarism when giving feedback. ELT Journal, 55(4), 375-381. doi:10.1093/elt/55.4.375

Llego, M. A. (2020). TeacherPH: On Plagiarised Articles of DepEd Community. TeacherPH. https://www.teacherph.com/plagiarised-articles-depedcommunity/

Mutya, R. A. (2020). An Open Letter to the Honorable Secretary of the Department of Education. Samahang Filipino Authors

Roman, A. (2018). Minimizing Plagiarism Incidence in Research Writing in One State

University in the Philippines. 